\title{
FABRICATION OF A HIGH SPEED MICROSCALE TURBOCHARGER
}

\author{
Hanqing Li, Nicholas Savoulides, Linhvu Ho, Stuart A. Jacobson, Ravi Khanna, Chiang-Juay Teo, \\ Li Wang, Dennis Ward, Alan H. Epstein, and Martin A. Schmidt \\ Massachusetts Institute of Technology \\ Cambridge, MA 02139
}

\begin{abstract}
Microscale turbocharger devices have been fabricated and tested. The device, formed by fusion bonding six silicon wafers, consists of a free rotor (with a compressor and turbine) contained within a static structure. A pressure differential across the turbine generates a torque that spins the rotor, producing flow and pressure rise through the compressor. This paper addresses fabrication issues critical to high speed operation of this device, such as journal bearing profile control, nozzle and thrust bearing process control and integration, rotor integration, and rotor imbalance, providing the first discussion of fabrication innovations developed specifically for the turbocharger. Preliminary test results are also included.
\end{abstract}

\section{INTRODUCTION}

A turbocharger has been fabricated as part of a program to build a microfabricated gas turbine generator (GTG) [1,2]. As the GTG is a highly complex system, its development has included several intermediate devices of increasing complexity. The turbocharger is far along the path to the GTG, lacking only the electric generator and having its turbine and compressor flow paths independent (Figure 1). The fabrication processes for the turbocharger are directly applicable to the GTG. As such, the turbocharger is a test vehicle for developing fabrication processes and turbomachinery/bearing technology.

Unlike previous devices in this program that had either a compressor or a turbine, the turbocharger rotor is formed from two aligned wafers, one containing a compressor and one containing a turbine. The turbocharger rotor diameter $(8.2 \mathrm{~mm})$ is twice that of previous devices. The increased mass of the rotor and its two wafer design place stringent requirements on the fabrication process. These requirements can be separated into two groups. The first results from tight specifications of the critical components that control the rotor performance, such as journal bearings, thrust bearings, and nozzles. The second results from factors that affect the imbalance of the rotor when spinning, such as mask misalignments and wafer bonding misalignment (in plane), and blade DRIE etch non-uniformity (out of plane).

\section{TURBOCHARGER STRUCTURE}

The micro turbocharger is a six layer fusion-bonded MEMS device as schematically shown in Figure 1 . The rotor is composed of a compressor in layer 3 (L3) bonded to a smaller diameter turbine in layer 4 (L4). The rotor is radially supported by a gas journal bearing located in the gap between the outer edge of the compressor and the stator ((6) in Figure 1). In some device builds, a second journal bearing is included in the gap between the outer edge of the turbine and the stator ((7) in Figure 1). The turbocharger is referred to as a dual bearing device when the turbine gap is $15 \mu \mathrm{m}$, small enough to act as a journal bearing, and as a single bearing device when the turbine gap is much wider, $50 \mu \mathrm{m}$ in the current design. The journal bearings are supplied with gas from a plenum (8) located in L4, on the backside of the compressor. A thrust bearing gap (6) is etched into L5 to provide vertical clearance that during operation is maintained by gas flow through nozzles (2) in both L2 and L5. The thrust bearing nozzles are supplied from plena (5) located in L2 and L5. Compressor blades (3) and turbine blades (4) are etched partly into L3 and L4 respectively. A SEM picture of a sectioned turbocharger is shown in Figure 2.

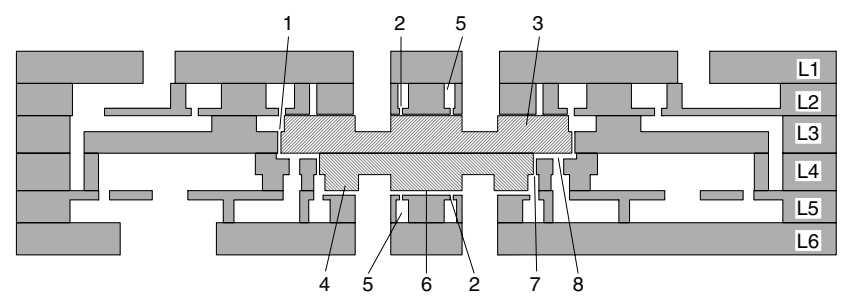

Figure 1. Cross-section of the turbocharger. The hatched structure is the rotor, free to spin within the device. Other critical components include: (1) compressor journal bearing, (2) thrust bearing nozzles, (3) compressor blades, (4) turbine blades, (5) thrust bearing supply plena, (6) thrust bearing gap etch, (7) turbine journal bearing, and (8) journal bearing supply plenum.

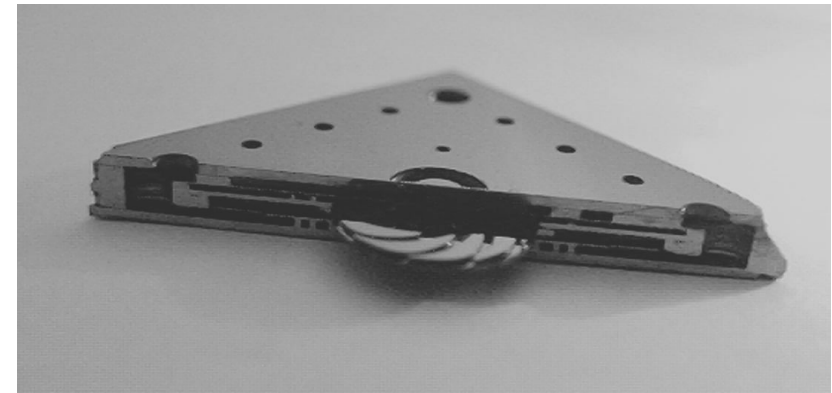

Figure 2. SEM picture of a sectioned turbocharger with rotor reinserted (taken from [2]). The device is formed by fusion bonding six silicon wafers. Die dimensions are $23 \mathrm{~mm} x 23 \mathrm{~mm} x$ $2.9 \mathrm{~mm}$. Compressor diameter $=8.2 \mathrm{~mm}$. Turbine diameter $=6.0$ $\mathrm{mm}$.

\section{JOURNAL BEARING PROFILE CONTROL}

The journal bearing is a narrow, deep and straight donut shape trench etched by DRIE into L3, and also into L4 in the dual bearing design, as seen in Figure 1. The design specifications are $16+/-0.75 \mu \mathrm{m}$ in width and $330 \mu \mathrm{m}$ in depth for the L3 compressor journal bearing, and $15+/-0.75 \mu \mathrm{m}$ in width and $330 \mu \mathrm{m}$ in depth for the L4 turbine journal bearing. These tight specifications make the journal bearing profile control a challenge.

One major difficulty we encountered in developing the journal bearing etch process was profile repeatability. Although in-spec journal bearing profiles could be obtained with our baseline DRIE (deep reactive ion etch) recipes [3,4], defects such as blowup tops (large initial openings that quickly taper down), steps, spikes, bellies, positive taper and negative taper appeared from time to time. We found that these defects were related to 
both DRIE conditions and inconsistency in masking material profiles.

The masking materials used in our device are a thick photo resist AZ9260 layer on top of a thermally grown silicon oxide film. The oxide film is included to protect the bonding surfaces of the wafers. Since it typically takes more than 4 hours to etch the narrow and deep journal bearings, two layers of the photo resist, totaling about $22 \mu \mathrm{m}$, are coated on the wafers. The journal bearing etch pattern is transferred to the photoresist by an integral exposure of $5 \times 15$ seconds, development in AZ440 for $2-3$ minutes, and post bake at $95^{\circ} \mathrm{C}$ for 30 minutes. The photoresist pattern is then transferred into the underlying oxide film with a BOE (buffered oxide etch) etch. The photo resist pattern edges have 40 to 60 degree slopes that depend mainly on the baking conditions. The oxide, though only 0.5 to $2 \mu \mathrm{m}$ thick, typically has a slope of 45 degrees or less. The etch rate of the photoresist is in the range of $2-3 \mu \mathrm{m} /$ hour and the etch rate of the oxide is about $1 \mu \mathrm{m} /$ hour. Figure 3 shows the resist etch rate dependence on DRIE chamber pressure. The etch rate decreases significantly with increasing SF6 pressure. The inset is a SEM picture of the resist and oxide profile.

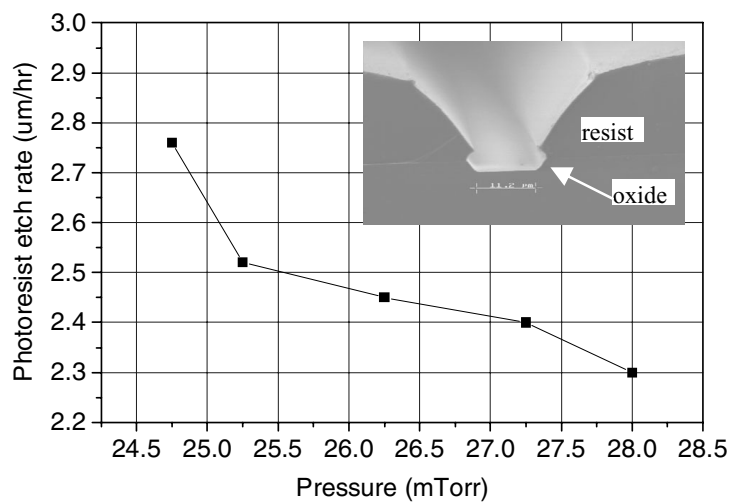

Figure 3. Photo resist AZ9260 etch rate vs. SF6 pressure. The inset is a SEM picture of the resist/oxide bi-layer profile after $B O E$ etch of oxide. The resist slope is the result of baking before BOE. The opening is about 9 um wide at the bottom of oxide.

Due to the long etch time required to achieve a depth of greater than $300 \mu \mathrm{m}$ in the silicon, the photoresist and oxide etch rates are large enough to result in significant mask material removal during the silicon etch. Thus the mask profiles determine the evolution of the journal bearing profiles. As the resist and oxide patterns recede from their original positions during DRIE, the opening of the journal bearing becomes larger. At the same time, with increasing depth, the amount of etching species needed to remove $\mathrm{Si}$ at the bottom and on the side of a straight journal bearing trench increases. If the masking materials recede faster than the speed at which the etching species can remove Si to make the journal bearing straight, a blow up or steps would appear in the journal bearing profile, as often seen in samples with shallow resist slopes. The SEM pictures in Figure 4 show the time dependence of the profiles of journal bearings patterned from the same mask ( $8 \mu \mathrm{m}$ width) and DRIE recipe. The oxide is $1 \mu \mathrm{m}$ thick and the resist is about $22 \mu \mathrm{m}$ thick for all these samples. After 1 hour and 2 hours the journal bearings remain straight. This is probably because of the low aspect ratio of the trench and the slower mask recession rate that is now still mainly determined by the BOE etched oxide slope. After 3 hours, however, a step of about 1-2 $\mu \mathrm{m}$ appears indicating a sudden change in the mask recession rate when the $1 \mu \mathrm{m}$ thick and roughly 45 degree slope in oxide is completely etched away and resist starts dominating the mask recession rate. As the etch continues, the step moves further down as shown by the arrows.

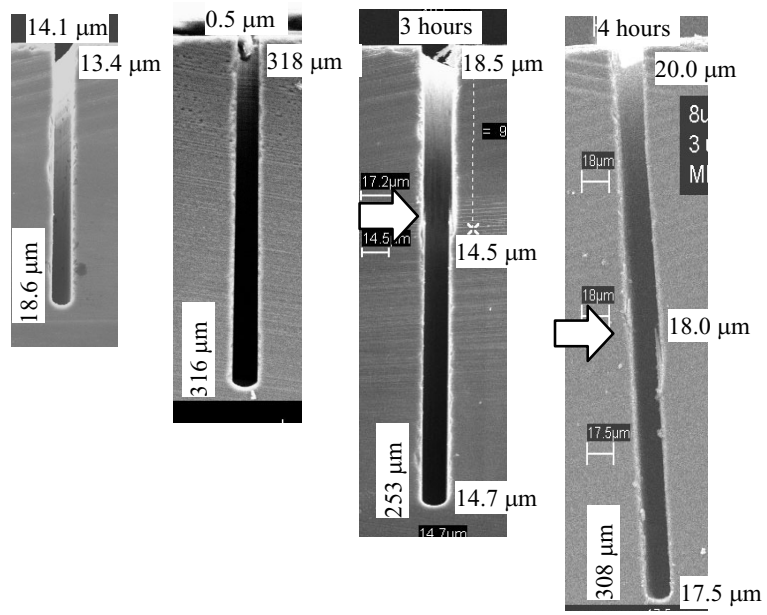

Figure 4. Journal bearing profile evolution with DRIE time taken from 4 samples prepared with same recipes. The photo mask width was $8 \mu \mathrm{m}$. The resist and oxide are $22 \mu \mathrm{m}$ and $1 \mu \mathrm{m}$ thick respectively. Steps shown by the arrows start to show after 3 hours and moved downward. The apparent tilt of the rightmost picture is just an artifact from the SEM.

With the same DRIE recipe and resist process, increasing the oxide thickness delays the appearance of steps or sudden width change in the journal bearing because the recession rate of the oxide is slower than that of the resist due to the slower etch rate of oxide (assuming similar slope), as seen in Figure 5. All three samples were prepared the same way except for their oxide thickness, $0.5 \mu \mathrm{m}, 1.0 \mu \mathrm{m}$ and $2.0 \mu \mathrm{m}$ from left to right. The DRIE etch was done for 4 hours. The step in the $0.5 \mu \mathrm{m}$ oxide sample is lower than in the $1.0 \mu \mathrm{m}$ oxide sample, and a straight journal bearing with no step is obtained in the $2.0 \mu \mathrm{m}$ oxide sample.
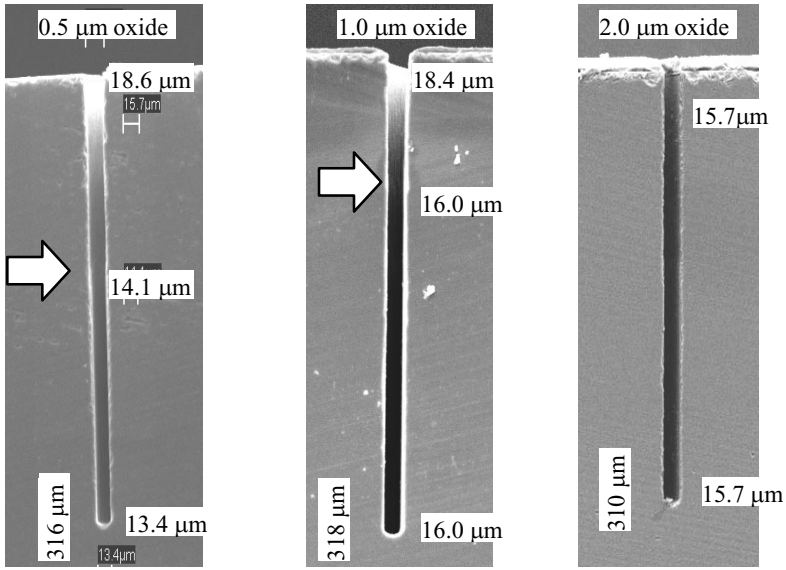

Figure 5. Influence of oxide thickness on journal bearings in 3 samples with different oxide thickness. Steps labeled by the arrows were visible in the $0.5 \mu \mathrm{m}$ sample, moved up in the $1.0 \mu \mathrm{m}$ sample and disappeared in the $2.0 \mu \mathrm{m}$ sample. Journal bearing depth is labeled on the left and width on the right of the trenches

Obviously increasing the resist slope angle can reduce its recession rate and therefore prevent the steps, but steeper slopes, if more than 45 degrees, could cause ion deflection onto the side walls of the journal bearing, eroding the passivation film thereon 
and forming bellies. Therefore to form narrow and straight journal bearings it is necessary to use a thick layer of oxide, $2 \mu \mathrm{m}$ or more, that gives a larger window in photoresist profile control, though with a cost of increased complexity in the BOE step.

However, a thick layer of oxide not only makes the photolithography and BOE etch hard to control, but also causes wafer bow. To avoid wafer bow, we use a LOCOS (local oxidation of silicon) oxide pattern for the journal bearing in our device. As an example, Figure 6 shows the layer 4 journal bearing process flow. Nitride film is deposited and patterned in step 3, as the LOCOS oxidation barrier. A thick thermal oxide film is grown locally in the pattern defined by the nitride pattern in step 5, followed by BOE and DRIE of the journal bearing in steps 6 and 7 , respectively. To protect the journal bearing from the subsequent blade etch (not shown) on the opposite side of the wafer, a thin layer of thermal oxide is grown in the trench, as seen in step 9. Another feature of this layer is a $30 \mu \mathrm{m}$ recess (the journal bearing supply plenum, (8) in Figure 1) that joins the journal bearing on one side. To form this recess without damaging the journal bearing profile, we use a nested mask that is patterned in step 2 and protected by nitride in step 9, and isotropically etch away a small Si ring adjacent to the journal bearing in step 11, which is now under the protection of oxide. The oxide in the journal bearing trench is now thicker than the oxide on the surface, so the surface can be stripped of oxide by a timed BOE (or HF) etch for bonding and there is still a protective layer of oxide inside the journal bearing, as seen in step 12 .

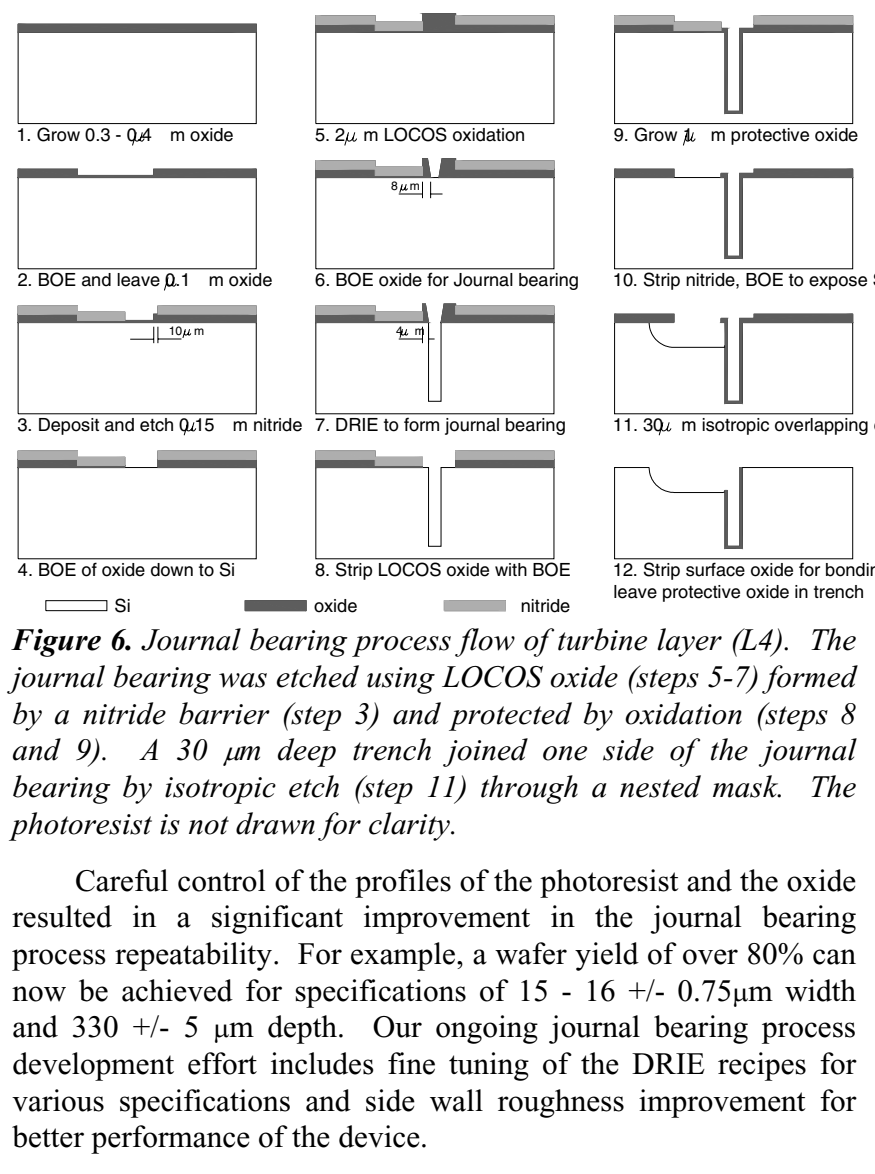

\section{THRUST BEARING AND NOZZLES}

A total thrust bearing gap (see Figure 1) of $5.5 \mu \mathrm{m}$ is etched into L5, and the rotor shifts axially downward by half this gap during centered operation, once it is freed. Each thrust bearing is supplied with pressurized air through 20 nozzle holes that are $100 \mu \mathrm{m}$ deep and $10 \mu \mathrm{m}$ in diameter, etched in L2 and L5. The process flow requires that these nozzles breakthrough into a $350 \mu \mathrm{m}$ deep plenum that has already been etched into the back of the wafers. Proper performance of the thrust bearings requires precise control of the nozzle dimensions and good uniformity between the nozzles. The nozzles have a mean diameter tolerance of $+/-1 \mu \mathrm{m}$ and mean length tolerance of $+/-10 \mu \mathrm{m}$, with allowable standard deviation between the nozzles about a factor of 5 less than the tolerances. Thus careful control of the photo process, BOE etch, and DRIE are necessary, as well as close inspections of both the nozzles and plena. For example, if nozzle patterning is done after the plenum DRIE, the protection of the bonding surface on the plenum side (usually protected with a layer of photoresist) is difficult to control because the baking before the nozzle BOE tends to make the protective resist flow away from the deep trench edges, exposing oxide there to BOE. When oxide undercut occurs, the Si bonding surface the oxide is supposed to protect is roughened by $\mathrm{BOE}$, resulting in a degradation of the wafer bonding strength. One possible solution we are exploring is to use DRIE to etch through both the oxide and $\mathrm{Si}$ on the nozzle side. The solution we are currently using successfully is to do the photolithography and BOE steps for the nozzles and plena at the same time.

\section{ALIGNMENTS AND ASSEMBLY}

As seen in Figure 1, the rotor of the turbocharger is a two layer structure, with compressor blades on top of L3 and turbine blades on the bottom of L4. L3 and L4 are bonded together before the blades on either side are etched, but after the journal bearings are etched. This bonding must be done with very small misalignment to minimize the rotor imbalance. Because the journal bearing trenches form sealed cavities when the two wafers are in contact, L3/L4 bonding is usually done in "fusion bonding" mode, in which the two wafers are separated by metal flags during alignment, clamped, pumped to about $10^{-3}$ torr, and pressed at room temperature in vacuum after the flags are pulled out. Due to post alignment clamping and flag motion, the fusion bonding mode usually has less alignment accuracy than the "silicon direct bonding (SDB)" mode, in which the wafers are put in contact in air right after alignment. The disadvantage of SDB mode is that any sealed cavity has trapped air in it that has the potential to cause plastic deformation of the $\mathrm{Si}$ wafer if annealed at high enough temperature.

To achieve better alignment in the rotor, we bonded L3 and L4 using the SDB mode of the bonder. The annealing was done at $600^{\circ} \mathrm{C}$ rather than the usual $1050^{\circ} \mathrm{C}$ to avoid plastic deformation. This is feasible because the subsequent blade etch opens the sealed journal bearing cavity and a high temperature annealing is done later for the final assembly. L3/L4 bonding misalignment of less than $2 \mu \mathrm{m}$ is regularly obtained with this process, with no bonding quality degradation observed from infrared images.

The misalignment between patterns, front to front or front to back, also contributes to rotor imbalance. Using a contact aligner, we can achieve mask misalignments of about $2 \mu \mathrm{m}$ or better. Further improvement should be possible with the use of a stepper and precise measurement of front to back misalignment.

\section{BLADE HEIGHT UNIFORMITY}

Another major source of rotor imbalance is DRIE etch nonuniformity of blades in L3 and L4. With the rotor diameter set at $8.2 \mathrm{~mm}$ and journal bearing depth set at $330 \mu \mathrm{m}$, blade depth 
variation has to be smaller than $3 \mu \mathrm{m}$ to meet the design imbalance specification. This limits blade heights to less than $250 \mu \mathrm{m}$ due to machine tolerance. The wafers are rotated multiple times during DRIE of blades to control depth uniformity. Figures $7 \mathrm{a}$ and $7 \mathrm{~b}$ show blade etch variation around the circumference of a compressor and SEM picture of the compressor blades. With careful process control, experimental measurements show that a typical rotor has its center of mass offset from its geometric center by $3-5 \mu \mathrm{m}$.

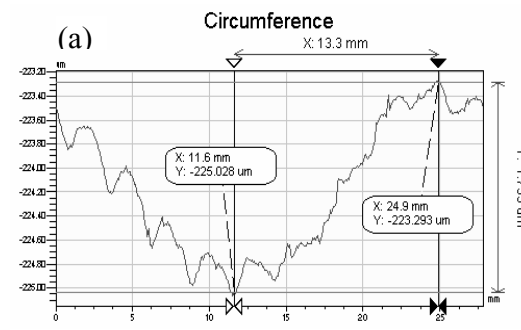

(b)

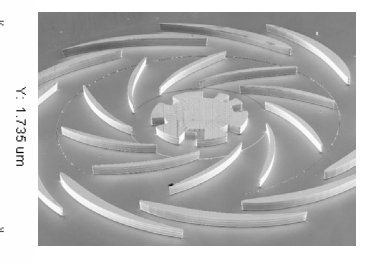

Figure 7. (a) Blade etch variation on the circumference of a compressor. The maximum peak-to-valley difference is $1.7 \mu \mathrm{m}$. (b) SEM picture of compressor blades of a single bearing device.

\section{ROTOR RELEASING}

Two ways for freeing the rotors were investigated. The first was to retain the rotor by bonding the center of the compressor top to oxide bonding pads in L2 before the L4 blade etch, and releasing the rotor with HF after dicing. This approach subjects the bonded wafers of L1 to L4 to several wet process steps and makes the wafer cleaning and bonding afterward very difficult. The current approach is to free the rotors from the L3/L4 stack, set them aside, finish all the layers, and drop the rotors back in during the final assembly. The free rotor method significantly simplifies the fabrication process. Although the free rotor approach eliminates the ability to perform fixed rotor flow tests, it opens the possibility for external characterization and dynamic balancing of the rotors prior to final assembly.

\section{TESTING}

During operation, turbine supply pressure is increased, and bearing pressures are adjusted to ensure rotordynamic stability. A high bandwidth fiber optic displacement sensor is used to measure rotor speed. Figure 8 shows measurements of the pressure ratio and mass flow rate obtained across the compressor for two runs of the same single bearing device. The compressor exhaust is throttled back to atmospheric pressure using an external valve. The throttle was set to a slightly different value for each of these runs. The compressor achieved a pressure ratio of $1.2(17 \%$ of design pressure rise) with a flow rate of $0.14 \mathrm{~g} / \mathrm{s}$ at $480,000 \mathrm{rpm}(40 \%$ of design speed). The measured pressure ratio is consistent with model expectations. The rotor destructively crashed at $460,000 \mathrm{rpm}$. The test data indicates that the crash resulted from the failure of the thrust bearings to provide sufficient angular stiffness to contain tilting torques applied to the rotor from asymmetries in the design. Further refinements to the fabrication process will be necessary to achieve design speed operation.
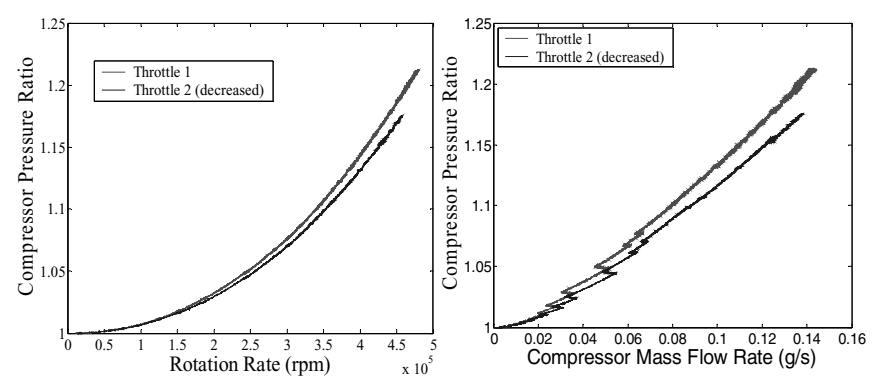

Figure 8. Test results for two different compressor throttle settings, showing significant pressure rise and flow rate through the compressor. The sharp flow rate changes occur when the journal bearing pressure is adjusted, which acts as a throttle on the compressor. Uncertainties: pressure ratio $+/-0.04$, flow rate $+/-0.004 \mathrm{~g} / \mathrm{s}$.

\section{CONCLUSIONS}

This paper discussed key fabrication issues related to the high speed operation of a microscale turbocharger. Proper control of the masking material profile was found to be critical for meeting the journal bearing dimensional specifications with high yield. Blade height uniformity of less than $2 \mu \mathrm{m}$ in the $8.2 \mathrm{~mm}$ rotors was achieved. The thrust bearing nozzle etch process was improved. A new free rotor method was developed to simplify the etching and assembly process. These process improvements resulted in a turbocharger device that achieved a speed of $480,000 \mathrm{rpm}$. Future work will focus on further improving rotor balance and process repeatability.

\section{ACKNOWLEDGEMENTS}

The authors would like to thank the staff of the MIT Microsystems Technology Laboratories for their help in fabrication. This work was supported by the Army Research Laboratory (DAAD19-01-20010) under the Collaborative Technology Alliance in Power \& Energy program, managed by Mr. John Hopkins (ARL) and Dr. Mukund Acharya (Honeywell), and by the Army Research Office (DAAG55-98-1-0292) managed by Dr. Tom Doligalski.

\section{REFERENCES}

1. Epstein, A.H., Senturia, S.D. et al., "Power MEMS and Microengines," Transducers '97, The $9^{\text {th }}$ International Conference on Solid-State Sensors and Actuators, Chicago, IL, June 1997.

2. Epstein, A.H., "Millimeter-Scale, MEMS Gas Turbine Engines," Paper GT-2003-38866, Proceedings of ASME Turbo Expo 2003, Atlanta, GA, June 2003.

3. Fréchette, L. G, Jacobson, S. A., Breuer, K. S., Ehrich, F. F., Ghodssi, R., Khanna, R., Wong, C.W., Zhang, X., Schmidt, M. A., and Epstein, A.H., "Demonstration of a Microfabricated HighSpeed Turbine Supported on Gas Bearings," Hilton Head SolidState Sensor \& Actuator Workshop, Hilton Head Island, SC, June 4-9, 2000, pp. 43-47.

4. Liu, L.X., Teo, C.J., Epstein, A.H., and Spakovszky, Z.S., "Hydrostatic Gas Journal Bearings for Micro-Turbomachinery," Paper DETC2003/VIB-48467, Proceedings of DETC'03, Chicago, IL, September 2-6, 2003. 